\title{
Study on e-commerce logistics cost control methods in the context of COVID-19 prevention and control
}

\author{
Qi Ding ${ }^{1} \cdot$ Huimin Zhao ${ }^{2}$
}

Accepted: 21 January 2021 / Published online: 11 February 2021

(C) The Author(s), under exclusive licence to Springer-Verlag GmbH, DE part of Springer Nature 2021

\begin{abstract}
The severe situation caused by THE COVID-19 epidemic has not only hindered the steady development of social economy, but also had a great impact on the development of e-commerce logistics. For e-commerce enterprises, logistics cost is an important factor that affects the operation effect and consumer experience. Based on this, this study proposes cost control methods for e-commerce logistics in the prevention and control of COVID-19 environment. In this study, based on the actual environment of COVID-19 prevention and control, the logistics cost algorithm during the epidemic period is designed on the basis of the analysis of the influencing factors of e-commerce logistics cost, and the cross-border logistics strategy that conforms to the background of COVID-19 prevention and control and the demand of e-commerce logistics cost control is developed to better reduce the operating cost of logistics enterprises. The e-commerce logistics cost control method proposed in this article is effective in the prevention and control of new crown pneumonia, and the overall actual cost is within the budgeted cost range. The experimental results prove that the e-commerce logistics cost control method designed in this paper can help e-commerce companies achieve good economic benefits and proves that it has higher application advantages.
\end{abstract}

Keywords COVID-19 $\cdot$ E-commerce logistics $\cdot$ Cost control $\cdot$ Cost influencing factors · Operating costs

\section{Introduction}

In early 2020, a severe outbreak of COVID-19 broke out in China. Due to the strong interpersonal transmission characteristics of COVID-19, the outbreak of COVID-19 has caused a huge impact on China's transportation, retail, labor-intensive manufacturing, export, real estate and other industries within a short period of time. In addition, the epidemic has had a serious negative impact on China's foreign trade, industrial and supply chains (Nguyen et al. 2018). For e-commerce firms, social media and their own e-commerce shops are important distribution platforms. Since the occurrence of the COVID-19 conflict, both streams have experienced greater growth. Nearly two-

Communicated by Vicente Garcia Diaz.

Qi Ding

dqi1971@126.com

Rizhao Polytechnic, Rizhao 276826, Shandong, China

2 Central University of Finance and Economics, Beijing 102206, China thirds of e-commerce firms and 70 percent of third-party online markets have significantly higher growth rates in mobile cash payments, supported by e-banking and credit card transactions. The other key steps proposed to be taken to encourage economic growth were the decreased prices for Internet and broadband connectivity, as well as telephone and other electronic payments. While considering cost-wise, e-commerce for trade in goods and services has been severely impacted by the same factors that have caused total supply and demand instability. During this pandemic, several other e-commerce-relate this problem that have emerged or been further exacerbated. These include cost value abstraction (i.e., rising prices to excessively elevated levels), concerns about product protection, misleading practices, concerns about cybersecurity, the need for bandwidth utilization, and issues associated with growth. Vendors, vehicle manufacturers, third-party logistics service providers, shipping firms and a variety of other vendors are bearing logistics costs throughout the distribution chain. Companies document logistics costs in various ways, some being as sophisticated as estimating the depreciation of inventory. 
In order to restore economic and social development, maintain export growth, and support industrial development and employment growth to stabilize the industrial chain, the development of e-commerce is of great significance. Because of the co-existence of logistics and e-commerce, the development of e-commerce enterprises cannot do without logistics (Bóna et al. 2018). Take crossborder e-commerce as an example. Currently, China's cross-border e-commerce enterprises are affected by COVID-19 epidemic and their own factors in the development process, and they still face many difficulties in logistics cost control. To this end, this study conducted a study on e-commerce logistics cost control methods in the context of COVID-19 prevention and control. This study is of great practical significance for strengthening the logistics cost control of China's current cross-border e-commerce enterprises. It is possible to describe logistics as an organized process involving the input, inventory and packaging, transportation of physical goods. E-Logistics is an Internet-enabled value chain for the provision of efficient logistics facilities, including commercial warehouse operations, export logistics, inventory systems, distribution management, sending systems, etc. The core points of outsourcing logistics amenities include low functional cost, map the variations in request and decrease principal savings. Several factors such as erroneous information, unreliable resources, sluggish and inadequate operations, and high product risk rates that arise as problems in corporate logistics specify the significance of accurate information exchange between various parties along the logistics value chain.

\section{Novel coronavirus pneumonia prevention and control cost control method}

\subsection{Analysis of factors affecting e-commerce logistics cost}

In terms of import and export trade, China has penetrated into many fields of global industrial and supply chains. Whether it is import or export, China is closely linked to all links of the global industrial and supply chains. The impact of the outbreak on China's foreign trade should not be limited to final consumer goods, but also include the impact of changes in the import and export of intermediate and capital goods on global industrial and supply chains.

From the perspective of export commodities, China's manufacturing industry is an important part of the global industrial supply chain (Ashley et al. 2018). The epidemic has led to a cliff like decline in China's exports of some commodities, and even a shortage of supply, leading to the rupture of the entire international commodity series. It will seriously affect the export of intermediate goods and capital goods in the short term, and cause some international supply interruption. If the outbreak of the epidemic delays the resumption of production and production of enterprises, foreign enterprises may use idle production bases to replace China's supply shortage, which will seriously affect the status of "made in China" in the global supply chain. In addition, the outbreak of disease and the shutdown of importers have reduced manufacturers' import demand for intermediate and capital goods, while the aviation embargo has restricted trade in certain high-value and low-weight products (Zhao et al. 2018).

Logistics cost control methods have a much tendency to improve vertical space utilization or bin re-profile as a means of achieving it, it increases storage density in bins \& racks. It helps to decrease shipping costs of both complete (FTL) and less than cartload (LTL) shipments by improving truck productivity. Moreover, reduces harm to specific instance containers by reducing transit movement and better use of usable floor-space to increase the volume of storage. It tends to encourage coordinated operations that are directly linked to labor, performance, use of assets and accuracy of inventory levels. The cost object is the commodity for which expenses are calculated or deliverable. In terms of the end user or purchaser of a service, E-Commerce usually describes price objects. Cost objects are partitioned into three forms: First, the general management or context of internal services is represented. Second, describing the organizational and strategic controller or execution units such as policy development, path management, service and distribution. Finally, representing the resources serving the profit objects.

This research is mainly to study e-commerce logistics outsourcing system, the system refers to the electronic commerce enterprise from upstream suppliers sourcing products and sales to consumers, delivery order in double outsourcing relay way, trunk line transportation by express delivery enterprises in the logistics business, the use of its geographical location widespread distribution network as delivery acceptance point of e-commerce platform, convenient consumers to send and receive the goods, and take "the last kilometer" of e-commerce order distribution tasks(Leng et al. 2018). According to logistics cost classification and cost object calculation, the composition of logistics cost is diverse. The composition of all kinds of logistics costs affects the accounting of logistics costs. In order to facilitate the calculation, the logistics costs are clearly divided. According to the payment method of logistics cost, logistics cost can be divided into internal payment cost and external payment cost where internal cost states to direct money making for any activity, and external payment cost refers to any unconditional circumstance from outwards effects (Dan et al. 2018). Outsourcing 
mainly refers to entrusted logistics cost, while internal purchase mainly includes labor, materials, depreciation, water and electricity, maintenance, etc. See Table 1 for details.

On this basis, logistics costs are classified according to circulation links, and the specific composition of logistics costs is shown in Table 2 .

Different accounting methods and angles of logistics cost have different effects on logistics cost of enterprises. Because of different accounting methods, their characteristics and emphases are different, even if the logistics cost is calculated under the same conditions, different results will be obtained. In the calculation process, enterprises should find their own methods according to their actual situation (Hmidet and Boubaker 2020). Based on this, it is necessary to further optimize the e-commerce logistics cost algorithm during the epidemic period.

\subsection{Cost calculation of e-commerce logistics during epidemic period}

With the outbreak of online shopping and the change of consumer psychology during the epidemic, enterprises must adjust the proportion of consumers in online shopping behaviors and its changes. On that epidemic, consumers have to wait for processing the elements for the need, and consumer proportion will varies due to their dynamic capability in way of life. During the epidemic prevention and control period, independent logistics channels should be avoided, and the two channels should be developed in parallel to promote the integration of online and offline channels (Zhang et al. 2019).

Generally speaking, commodity price and logistics service level affect the market demand of three. The demand decreases with the increase of price and increases with the improvement of logistics service level. Then, the following formula exists:

$d=a-\beta p+y q$

where $a>0$ is the basic demand of the market, $p$ and $y$ correspond to the sensitivity coefficient of price and service level, respectively, and $p>0, y>0$. E-commerce enterprises decide their order quantity $q$ according to market demand. If there is no shortage of goods, then $q=d$. It is assumed that all participants are risk neutral, that is, there is no risk cost to pay, and the market information is complete, that is, the information such as the cost and market demand of each participant are common knowledge and understood by all parties (Zheng and Sun 2019).

Suppose the unit operating cost of express delivery enterprise is $\mathrm{k}$, and the unit freight rate is s. Theoretically speaking, assuming that it does not have the limitation of capacity supply, it can meet any logistics service level required by e-commerce enterprises. However, incremental operating costs are required to improve the service level. The calculation process is as follows:

$g(s)=\frac{1}{2} d k s^{2}$

In order to determine the unit, cost of e-commerce operation and speed up the quotation of $K$ for e-commerce enterprises, the unified warehouse docking is not considered here, and the e-commerce enterprises do not use the daily e-commerce distribution system to realize the delivery of some orders to the store, so as to reduce the cost and reach the $C$ value. Therefore, it can be regarded as a fixed value independent of logistics service level. In addition, we must satisfy the positive number of $Q, S, P$

$2 k \beta-y^{2}>g(s), \alpha-\beta\left(c_{A}+c_{B}+c_{C}\right)>0$

Through the analysis of market demand, price and product cost structure, the cost level of each participant is determined, and the cost function of the whole system is established. Based on this model, the decision-making process and revenue of logistics outsourcing of e-commerce enterprises are analyzed. The cost calculation of electronic industry is as follows:

$\pi_{A}=\left(p-w_{B}-w_{C}-c_{A}\right) q 2 k \beta-y^{2}$

Further, the express cost of e-commerce logistics industry is calculated

$\pi_{B}=\left(w_{B}-c_{B}\right) q-g(s)=\left(w_{B}-c_{B}\right) q-\frac{1}{2} k s^{2}$

The labor cost of e-commerce logistics industry is calculated as follows:
Table 1 Composition of logistics cost (classified by payment form)

\begin{tabular}{ll}
\hline Project & Concrete content \\
\hline Material cost & Including material cost, fuel cost and other assistance tools consumption \\
Labor cost & Salary, welfare, maintenance fee \\
Maintenance fee & Maintenance cost, rent, etc \\
Water and electricity & Water, electricity and gas used in logistics process \\
Depreciation charge & The consumption of houses, tools, etc. to be used in circulation \\
Entrusted logistics fee & Packing, transportation, storage, etc
\end{tabular}


Table 2 Composition of logistics circulation cost

\begin{tabular}{ll}
\hline Project & Concrete content \\
\hline Transportation cost & Labor cost and vehicle related cost in transportation \\
Storage cost & Inventory holding cost, order cost and shortage cost \\
Packaging cost & Labor cost, material cost, etc \\
Distribution cost & Vehicle related costs, sorting labor costs, etc \\
Handling cost & Handling labor costs, machinery costs, auxiliary costs, etc \\
\hline
\end{tabular}

$\pi_{C}=\left(w_{C}-c_{C}\right) q$

The cost algorithm of the whole industry alliance of ecommerce logistics industry is as follows:

$$
\begin{aligned}
\pi_{\mathrm{r}} & =\pi_{A}+\pi_{B}+\pi_{C} \\
& =\left(p-c_{A}-c_{B}-c_{C}\right) q-g(s) \\
& =\left(p-c_{A}-c_{B}-c_{C}\right) q-\frac{1}{2} k s^{2}
\end{aligned}
$$

In the above formula, $A$ represents the online part of ecommerce enterprises, $B$ represents logistics enterprises, and $C$ represents the offline part of e-commerce enterprises. Taking the online and offline parts of e-commerce enterprises and logistics enterprises as a virtual whole to make logistics centralized decision-making is equivalent to taking e-commerce enterprises to undertake the full closedloop decision-making from online trading to offline distribution (Han et al. 2019). Participants will consider the maximum cost between systems, not transaction costs, and will determine order quantity $Q$ and logistics service level $S$. Therefore, the following relationship exists:

$q=\alpha-\beta p+y s$

It can be concluded that:

$p=\frac{\alpha+y s-q}{\beta}$

Further, the overall cost is obtained

$\pi_{T}=\left(\frac{\alpha+y s-q}{\beta \pi_{\mathrm{r}}}-c_{A}-c_{B}-c_{C}\right) q-\frac{1}{2} k s^{2}$

According to the environmental background of COVID19 , participants participating in order allocation, as independent business entities, should reasonably determine the value of each variable to maximize their own cost. In addition, the decision-making process is a gradual process, which belongs to the category of game (Schne et al. (2018)). That is, two interrelated games are formed between the online and offline parts of e-commerce enterprises and logistics enterprises, and the optimal values of each decision variable are obtained through reverse induction. The results are as follows:
$w_{B C}^{*}=\frac{2 k \alpha-y^{2}\left(c_{B}+c_{C}\right)+2 \mathrm{k} \beta\left(c_{B}+c_{C}-c_{A}\right)}{4 k \beta-y^{2}}$

$s_{1}^{*}=\frac{y\left[\alpha-\beta\left(c_{A}+c_{B}+c_{C}\right)\right]}{4 k \beta-y^{2}}$

$q_{1}^{*}=\frac{k \beta\left[\alpha-\beta\left(c_{A}+c_{B}+c_{C}\right)\right]}{4 k \beta-y^{2}}$

$p_{1}^{*}=\frac{3 k \alpha+\left(k \beta-y^{2}\right)\left(c_{A}+c_{B}+c_{C}\right)}{4 k \beta-y^{2}}$

Further get the cost of each party and consumption:

$\begin{aligned} \pi_{A 1}^{*} & =\frac{k^{2} \beta\left[\alpha-\beta\left(c_{A}+c_{B}+c_{C}\right)\right]^{2}}{\sum \lim _{0 \rightarrow \infty} s_{1}^{*}\left(4 k \beta-y^{2}\right)^{2}+w_{B C}^{*}\left(p_{1}^{*}-q_{1}^{*}\right)} \\ \pi_{B C}^{*} & =\frac{k\left(4 k \beta-r^{2}\right)\left[\alpha-\beta\left(c_{A}+c_{B}+c_{C}\right)\right]^{2}}{\sum \lim _{0 \rightarrow \infty} s_{1}^{*} 2\left(4 k \beta-y^{2}\right)^{2}+w_{B C}^{*}\left(p_{1}^{*}-q_{1}^{*}\right)}\end{aligned}$

For the whole logistics outsourcing system with two kinds of small alliances, the decision of e-commerce enterprises' small alliances is neutral, the members realize transfer price through contract, but the decision of nonsmall alliances is independent, and all parties are pursuing their own maximization (Zhang et al. 2020). This process takes three forms:

1. The alliance of express delivery industry and e-commerce is equivalent to the whole process of express company from e-commerce warehouse to consumers' self-operation, and terminal outlets are arranged by themselves; The static merger is formed when a new child brand is operating by that of the parent companies.

2. The alliance between express delivery industry and e-commerce enterprises is equivalent to the core competitiveness of e-commerce self-supporting distribution and rapid development; When two or more firms sign a business agreement to pool their capital and capabilities together, a non-equity strategic alliance is formed.

3. E-commerce and its alliance are equivalent to the selfsupporting terminal of e-commerce.

On this basis, the market is segmented according to the different needs of the target market for the product or 
marketing mix. At the same time, enterprises can also locate appropriate target consumers. By determining the segmentation variables and the segmentation market, the detailed outline of the segmentation market is drawn and the consumer demand of the target market is found (Wang 2019). When one business buys a certain multiplied by the amount of the other enterprise, an equity strategic alliance is produced.

The market segmentation strategy is to divide the market into various specific customer groups in order to provide differentiated services to various consumers. The main purpose of market segmentation is to differentiate products or services. Such differentiation will help enterprises to sell more products or services at a premium, increase market competitiveness in the corresponding market and help enterprises to further develop and expand. Market segmentation needs to be easy to quantify analysis, and seek the differentiation market with large profit space and low entry threshold. Through product segmentation, enterprises can find a blue ocean market with richer costs and relatively small competition. After seeking a market segment that is easy to compete with through consumer demand, enterprises can easily enter.

\subsection{Realization of e-commerce logistics cost control}

Logistics cost prediction is to make a scientific estimate of the future cost level and its changing trend by mastering the historical data of logistics cost and the specific development situation of the enterprise, combining with the logistics management objectives and using certain technical methods. Cost prediction is the basic work of cost decision-making, cost planning and cost control, which can improve the scientific nature and predictability of logistics cost management. Logistics decision-making is based on the results of the forecast, the choice of appropriate methods (including determining the mode of transportation and personnel) for economic forecasting and effect analysis (Jafari et al. 2019).

Order processing is the process in which customer can view and fulfill the requirements based on their needs by selecting, padding and processing the products. Supplier Exchange facilitates online cooperation between consumers and various forms of manufacturing industry firms, including suppliers of distribution facilities, outside suppliers, suppliers of seek customer and discrete vendors of purchasing orders. Sorting is a system to assemble the products in several form in terms of destination wise, product, user need, more sight to identify the products effortlessly for processing it. The purpose of storage is to supply a product according to the clients need from warehouse and to make a stable stream to market.
Logistics cost prediction, decision-making and planning are the content of logistics cost control, which can actively control costs and improve control efficiency. Pre-control is the control of the circulation process. It mainly corrects the errors in time according to the control standards, strictly supervises and reviews the logistics costs generated in the daily logistics activities, ensures the standardization of the logistics process, reduces unnecessary losses and embodies the characteristics of timely discovery and timely correction (Tang et al. 2018). Accounting and feedback analysis belong to post control. The two are closely combined, that is, after the implementation of control, the cost accounting data are further processed and calculated to reflect the specific form of logistics cost. Second, through data analysis, the feedback of logistics cost control in the next step is predicted (such as rewards and punishments for relevant personnel to perform their duties, optimization of process links, etc.), so as to improve the level of logistics cost control in the next step. Figure 1 shows the emphasis and complementarity between the three main components of logistics cost control.

Freight charges include freight charges at the company's internal freight stations and freight charges paid by the partner logistics company. Internal traffic expenses include the salary of traffic personnel and vehicle related expenses. The external entrusted logistics cost can be calculated according to the requirements of partners and the weight of products. It can realize the function of cost management in two aspects. One is to reflect the viewpoint of cost allocation in the process of activity-based cost allocation. Second, through the analysis of the necessity and rationality of the existence of the enterprise, to judge whether the enterprise has value-added functions, such activity-based cost control process belongs to the process view.

On this basis, the vertical representation can also be used to realize the logistics cost management. The structure of logistics cost management model based on vertical representation is shown in Fig. 2.

Vertical representation is the calculation process in the activity-based cost management model of commodity logistics. It returns resources to activities, analyzes which activities consume products or services, calculates the amount of activities and finally realizes the distribution of products. The information of these dimensions can help enterprises to make e-commerce logistics decisions, including determining the price of products, changing the type of products, and so on. In this process, it is necessary to analyze cost drivers, evaluate improvement measures and realize dynamic control, so as to improve the process of enterprise value chain, so as to achieve the purpose of reducing costs, expanding costs and improving customer satisfaction. 
Fig. 1 Logistics cost control block diagram
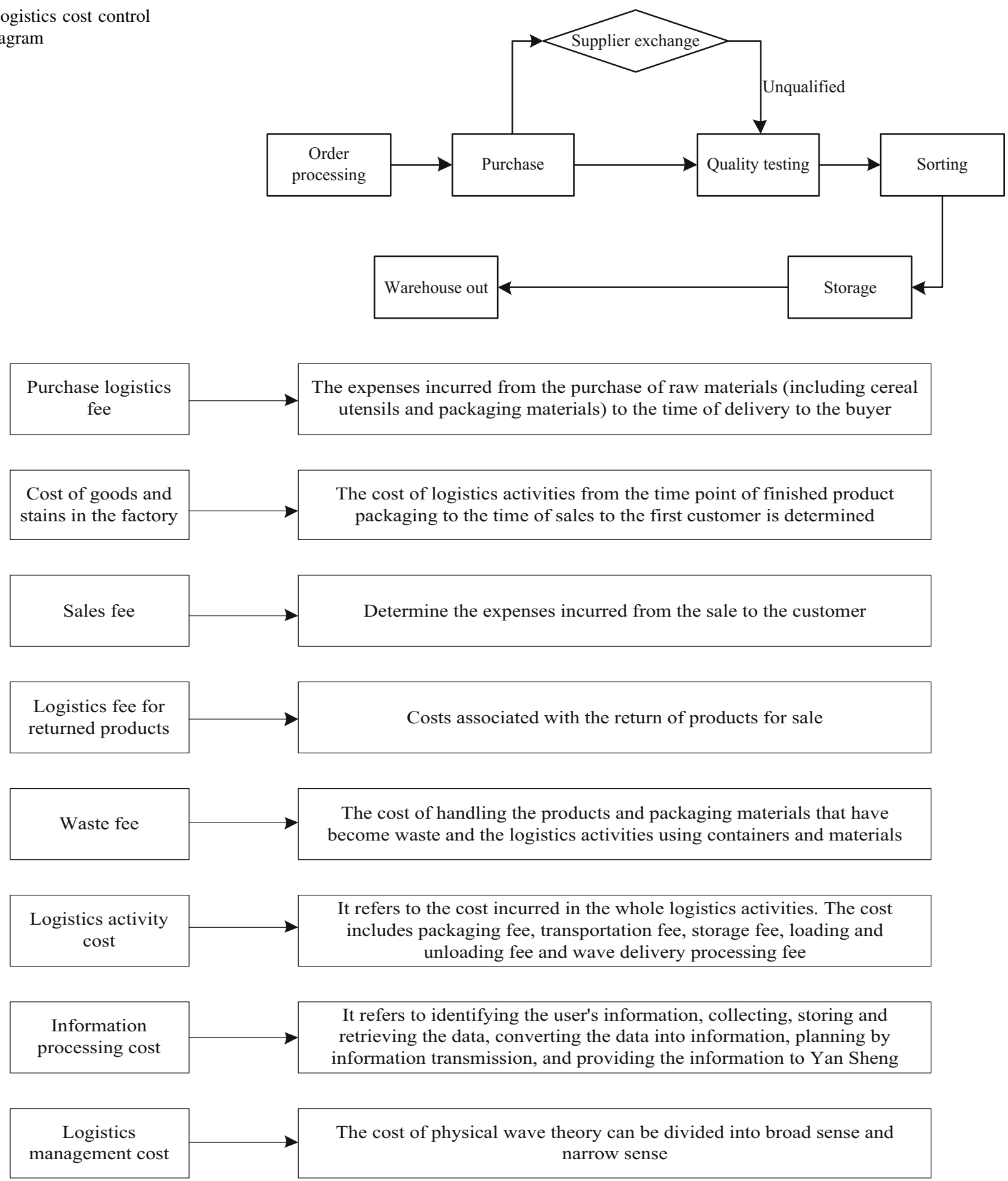

Fig. 2 Logistics cost management model based on vertical representation

To sum up, the ultimate goal of activity-based costing for e-commerce enterprises in logistics cost control is to reduce or avoid the consumption of logistics resources and reduce logistics costs, so as to continuously improve the profitability and business space of enterprises. The aim of the plan is to identify which factors lead to excessive spending and what measures can be taken to eliminate or mitigate these effects. The logistics cost management based on vertical representation can realize the logistics cost management of e-commerce enterprises. The combination of the two can effectively control the logistics cost of e-commerce enterprises and lay the foundation for the 
stable development of e-commerce industry under the epidemic environment.

\section{Empirical analysis}

In order to verify the practical application effect of e-commerce logistics cost control methods in the context of COVID-19 prevention and control, the following verification experiment is designed. The logistics cost data of an e-commerce enterprise in the past six months are selected for follow-up investigation and empirical analysis, and three basic parameters of the enterprise, namely average planned budget cost (BCWS), completed budget cost (BCWP) and actual cost (ACWP), are comprehensively evaluated and recorded. Average planned budget cost (BCWS) is an estimated expense that defines a cost for every transaction from the lower end to higher end and manages overall average accounting. Completed budget cost (BCWP) is a total projected cost need to complete a development including financial, accounting of all actions and management.

Actual cost defines a real value of either product or service that determines based on operation. performance index (CPI)ratio refers to the cost performance index (CPI) is an indicator of a long-term financial quality and effectiveness. For every unit of cost expended, it reflects the amount of completed work. As a proportion, the cost of the work done by the estimated cost of the work performed. It Minimize the total cost of three key components: stock operating expenses, order assignment costs and shortage costs. The representation is carried out for the production of a model to determine the cost parameter with many parameters of transport distance. The evaluation curve of

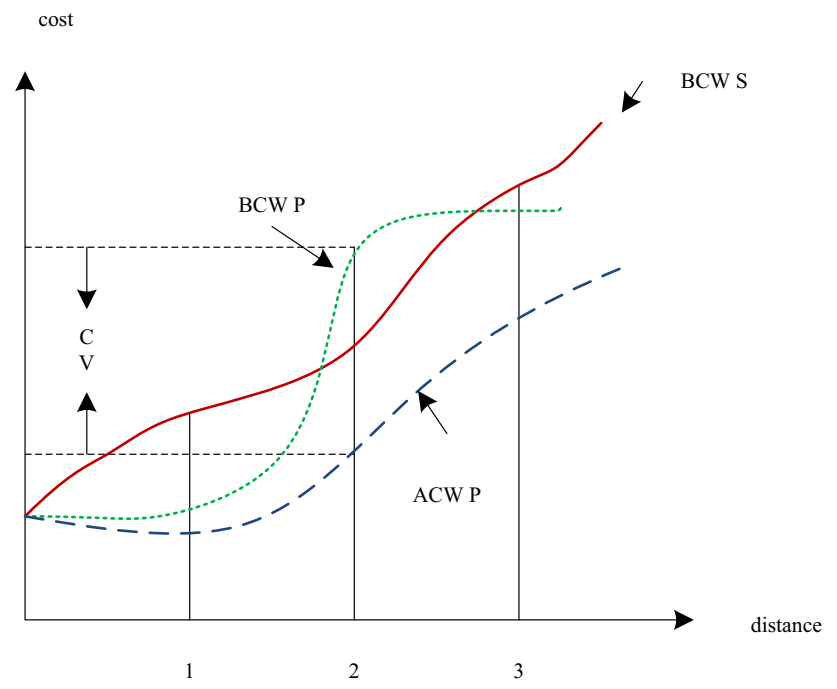

cost control parameters is shown in Fig. 3 where dimensions like distance and cost are measured to evaluate the metrics like CV, BCWP, ACWP, BCWS. Among those, BCWS takes most valuable cost that specifies the outcome.

Based on the above three basic cost parameters, four important evaluation indexes are designed:

Firstly, the control deviation is calculated, which is also the difference between the estimated cost and the actual cost of the project

$\mathrm{CV}=\mathrm{BCW} \mathrm{P}-\mathrm{ACW} \mathrm{P}$

If the calculation result of $\mathrm{CV}$ is negative, it indicates that the actual cost exceeds the budget and the cost control effect is not good. If the calculated value is positive, the actual cost does not exceed the budget, and the cost control effect is good. Performance index (CPI) is the ratio of budget cost to actual cost, and its calculation formula is as follows:

$\mathrm{CPI}=\mathrm{BCW} \mathrm{P} / \mathrm{ACW} \mathrm{P}$

If the calculation result of $\mathrm{CP}$ does not exceed 1 , it means that the actual cost exceeds the budget and cannot be controlled. If the $\mathrm{CP}$ value is greater than, it indicates that the actual cost is within the budget, and the cost control is effective. Further calculation of the performance index (CPI) is the ratio of the budget cost to the actual cost, and the calculation formula is as follows:

$\mathrm{SV}=\mathrm{BCW} \mathrm{P}-\mathrm{BCW} \mathrm{S}$

In addition, the ratio between the actual implementation progress and the budget progress of the project is calculated as follows:

$\mathrm{SPI}=\mathrm{BCW} \mathrm{P} / \mathrm{BCW} \mathrm{S}$

Through the in-depth comparison and analysis of the calculation results of the above four indicators, the changes in related hidden influencing factors such as cost, labor and raw materials are found, and the advance budget and cumulative schedule are calculated, as shown in Table 3.

At the same time, through in-depth comparative analysis of the calculation results of the above four indicators, the change curve of cost control evaluation is further drawn, as shown in Fig. 4.

As shown in Fig. 4, the BCWS curve shows an upward trend. Since the POSITION of ACWP curve is lower than that of BCWP curve, it indicates that the actual cost is within the budget, the logistics progress is progressing smoothly according to the original plan, and the whole project is in good condition.

Further record the actual cost accumulation and the actual progress accumulation structure, the specific results are shown in Table 4.

Fig. 3 Cost control parameter evaluation curve 
Table 3 Planned budget cost and planned cumulative progress

\begin{tabular}{|c|c|c|c|c|c|c|c|c|}
\hline \multirow[t]{3}{*}{ Planned budget cost (yuan) } & \multicolumn{8}{|c|}{ Planned cumulative progress } \\
\hline & \multicolumn{4}{|l|}{2019} & \multicolumn{4}{|l|}{2020} \\
\hline & September & October & November & December & January & February & March & April \\
\hline $2,475,336$ & 0.06 & 0.26 & 0.41 & 0.51 & 0.61 & 0.66 & 0.86 & 0.92 \\
\hline
\end{tabular}

Control evaluation parameters

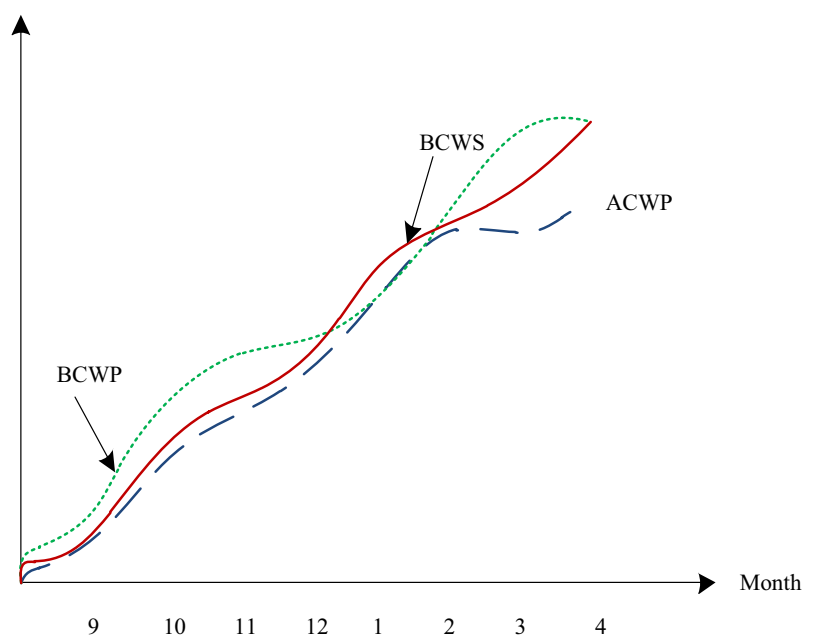

Fig. 4 Cost control evaluation curve

Based on Table 4 and the detection results of the cost control evaluation curve, it can be found that the proposed cost control method of e-commerce logistics in the context of COVID-19 prevention and control has a good effect. The overall actual cost expenditure is within the budgeted cost range and meets the expected standard, which can help e-commerce enterprises achieve good economic benefits.

\section{Conclusion}

In view of the characteristics of e-commerce enterprises, this study discusses the cost control of e-commerce logistics links, conducts a theoretical analysis first, and then makes an in-depth analysis combining with practical cases. The results of this study on the impact of standard costing on logistics based on product factors such as e-Commerce sales and maintenance. According to the results of the report on the relationship between cost control, budgeting and profitable accounting, it was evident that there exists a significant and strong positive relationship between cost control and e-commerce business. First of all, find out the status quo of e-commerce enterprise logistics cost control and the common problem, and in-depth analysis of the influencing factors of electric business logistics cost, and then combined with the homework cost method-based e-commerce enterprise logistics cost control and vertical representation based on logistics cost management can be realized to the electronic commerce enterprise logistics cost effective control.

Cross-border electricity for promoting the social and economic development of our country has an important value and function, strengthen the control and management of logistics cost is the key content of electricity distribution, analysis of overseas warehouse model means crossborder electricity business logistics costs under control, can effectively strengthen cost control, improve company's overall efficiency and market competition ability, and for the efficient work of cross-border electronic business logistics cost control to lay the foundation. Our future work
Table 4 Accumulated actual cost and actual progress

\begin{tabular}{llll}
\hline Particular year & Month & Accumulated value of actual cost (yuan) & Cumulative actual progress \\
\hline 2019 & September & 110,867 & 5.2 \\
& October & 592,518 & 25.4 \\
& November & 973,466 & 42 \\
2020 & December & $1,186,673$ & 51 \\
& January & $1,350,517$ & 59 \\
& February & $1,574,251$ & 64.5 \\
& March & $2,057,225$ & 87 \\
& April & $2,368,972$ & 100
\end{tabular}


is to make a research on the actions of consumers toward a commodity and also in logistics is required to map the association and further accounting must be done to bridge the gap in cost management, inventory valuation and budgetary control.

Author contributions DQ: Conceptualization, Methodology, Software, Data curation, Writing- Original draft preparation; ZH: Visualization, Investigation, Supervision, Validation, Writing- Reviewing and Editing.

\section{Compliance with ethical standards}

Conflict of interest The authors declare that thtey have no conflict interest.

Research involving human participants and/or animals There is no human participants and/or animals.

Informed consent Not Applicable.

\section{References}

Ashley CO, Evan C, Jacob T et al (2018) Comparing building and neighborhood-scale variability of $\mathrm{CO}_{2}$ and $\mathrm{O}_{3}$ to inform deployment considerations for low-cost sensor system use. Sensors 5:1349

Bóna K, Róka S, Dávid L (2018) Mathematical modelling of the cost structure of the logistics system of shopping malls in budapest. Period Polytech Transp Eng 3:142-150

Dan Y, Yong Y, Yingping $\mathrm{H}$ et al (2018) Low-cost wireless temperature measurement: design, manufacture, and testing of a PCB-based wireless passive temperature sensor. Sensors 2:532

Han SY, Zhong XF, Chen YH et al (2019) Fuzzy guaranteed cost hoc control of uncertain nonlinear fuzzy vehicle active suspension with random actuator delay. Int J Fuzzy Syst 7:2021-2031
Hmidet A, Boubaker O (2020) Real-time low-cost speed monitoring and control of three-phase induction motor via a voltage/ frequency control approach. Math Probl Eng 2:1-14

Jafari MR, Khanzadeh M, Tian W et al (2019) From in-situ monitoring toward high-throughput process control: cost-driven decision-making framework for laser-based additive manufacturing. J Manuf Syst 5:29-41

Leng L, Zhao Y, Wang Z et al (2018) Shared mechanism-based selfadaptive hyperheuristic for regional low-carbon location-routing problem with time windows. Math Probl Eng 17:1-21

Nguyen L, Moseson AJ, Farnam Y et al (2018) Effects of composition and transportation logistics on environmental, energy and cost metrics for the production of alternative cementitious binders. J Clean Prod 1:628-645

Schne T, Jasko S, Simon G (2018) Embeddable adaptive model predictive refrigerator control for cost-efficient and sustainable operation. J Clean Prod 20:496-507

Tang XM, Yang S, Yu JM et al (2018) Guaranteed cost control of networked control systems with bounded packet loss based on quantization dependent lyapunov function. Acta Autom Sin 8:1381-1390

Wang JQ (2019) Path following of a surface ship sailing in restricted waters under wind effect using robust $\mathrm{H} \propto$ guaranteed cost control. Int J Naval Archit Ocean Eng 1:606-623

Zhang Z, Wang C, Guang C et al (2019) Cost-saving and control investigation for isopentyl acetate ionic liquid catalyzed synthesis through conventional and dividing-wall reactive distillation. Process Saf Environ Prot 1:89-102

Zhang X, Zhang Z, Wang Y et al (2020) Guaranteed cost control of genetic regulatory networks with multiple time-varying discrete delays and multiple constant distributed delays. IEEE Access $1: 1-13$

Zhao Q, Wang W, De Souza R (2018) A heterogeneous fleet twoechelon capacitated location-routing model for joint delivery arising in city logistics. Int J Prod Res 15-16:5062-5080

Zheng Z, Sun D (2019) Model predictive flux control with cost function-based field weakening strategy for permanent magnet synchronous motor. IEEE Trans Power Electron 2:2151-2159

Publisher's Note Springer Nature remains neutral with regard to jurisdictional claims in published maps and institutional affiliations. 